\section{Trench warfare at Sundsvall}

\section{London}

THE first step on the long road to an international agreement to combat global warming was completed last week in Sundsvall, Sweden, when delegates from 74 nations reached agreement on the final text of the report from the Intergovernmental Panel on Climate Change (IPCC). The report will be used to begin negotiations on an international climate change convention, similar to the Vienna Convention which provided the impetus for efforts to protect the ozone layer. But negotiations will be difficult, with a group of nations led by the United States opposing urgent action to limit greenhouse gas emissions.

Earlier in the meeting, Peter Timeon, foreign secretary of the tiny South Pacific nation of Kiribati, made an impassioned plea for stronger action from the industrialized nations. His country is one of those most as risk from the sea-level rise predicted if global warming continues unchecked. But his words apparently went unheeded by US, Soviet and Saudi Arabian officials, who resumed their painstaking battle over the report's precise wording with the European representatives who were supporting early action.

The report's important role in framing a climate change convention explains the almost absurdly slow debate over its contents, likened to "trench warfare" by one observer in Sundsvall. US delegates, concerned about the impact of a rigorous anti-global warming strategy on the US economy, fought strongly to introduce references to the scientific uncertainties

\section{No blurry smudge, this Hubble photograph}

NASA, the National Aeronautics and Space Administration, last week released its second batch of impressive stellar photographs from the Hubble Space Telescope to prove that the orbiting observatory is far from blind.

One image (right), taken with the European Space Agency's Faint Object Camera, shows a mysterious elliptical ring of glowing material around the remnants of Supernova 1987A.

NASA astronomers said that the ring is destined to be a relatively short-lived structure. Expanding debris from

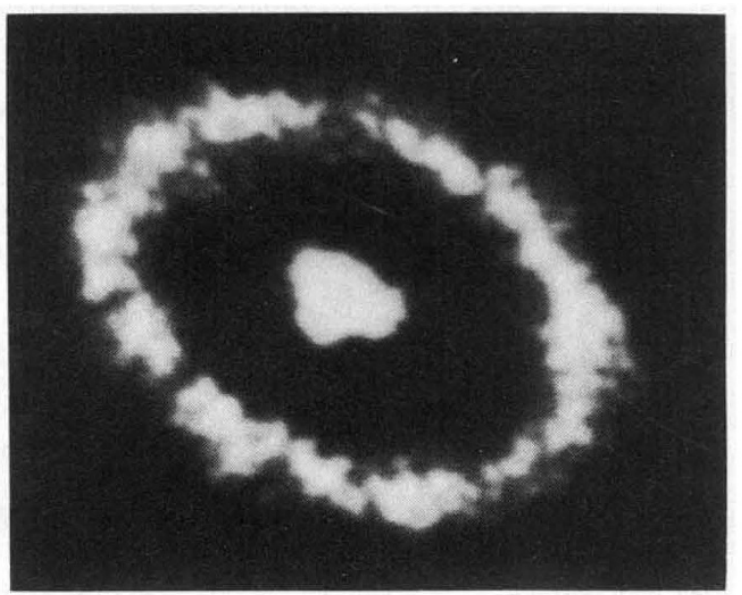

the explosion (now delineated by the blob at the centre of the ring) will overtake and disintegrate the ring within a century.

Resolution of the image is 0.1 arc second, an unprecedented level of detail but still nearly an order of magnitude from the camera's intended focus. Although other Hubble components are likely to reach their full design specifications after upgrades in future years, images from the Faint Object Camera may never get much better than this (see Nature 346, 781; 30 August 1990). surrounding climate predictions and the the economic costs of measures to combat the greenhouse effect have not En adequately calculated.

what they saw as US attempts to undermine the report. John Houghton, from the UK Meteorological Office, chairman of IPCC's working group I, concedes that looking for a strong line from PCC may be disappointed. But IPCC was set up to define the options in combating produce a do Houghton says. He adds that the US delegation could have blocked the adoption of the report in Sundsvall, but did not do

The Sundsvall meeting produced a conuding overview to link the reports from IPCC's three working groups, which have looked at the science and impacts of cli. em. The individual working groups reports (on which the overview is based) official release of the impacts and responses reports was delayed until the undsvall meeting.

A leaked early draft of working group (to global warming, was attacked by environaroups for the modest targets it sions: the proposals for each region broadly paralleled the existing positions of governments (see Nature 345, 373; 31 1990). The final version has dropped the suggested emission targets, instead discussing in more general terms the

various strategies governments may adopt, from adapting to climate change through to energy efficiency measures and cuts in greenhouse gas emissions.

Fiona Wier, Friends of the Earth's delegate in Sundsvall, says the final report does little to quantify the reduction in carbon dioxide emissions that could be achieved very quickly through increased energy efficiency, arguing that its proposals "could have been written on the back of an envelope two years ago". But she is pleased that the specific, but modest, suggested emission targets have now been left out. During the lengthy negotiations towards a climate convention, individual countries may take unilateral action to cut their emissions. Wier believes these moves would have been restricted if group III's original draft had been incorporated into the final IPCC report.

Although IPCC's primary function was to produce the now-completed report, Houghton says that it will have an important role to play in the continuing climate convention negotiations, providing regular scientific and technical updates for the negotiating teams. Peter Aldhous HUMAN GENOME PROJECT

\title{
Database goes on-line
}

\section{London}

Geneticists gather in Oxford this week to test a new computer database for the Human Genome Project. The database, developed by a team led by Richard Lucier from Johns Hopkins University, Baltimore, Maryland, should become available to genome mappers later this month.

The new database will contain basic gene-linkage data, information on polymorphism, and practical details on genetic probes and the location of laboratory material. The genetic sequences themselves are deposited in the Genbank database at the Los Alamos laboratory, but Lucier says that discussions to allow the exchange of data with Los Alamos are under way.

Similarly, the database will be linked up to the existing On-line Mendelian Inheritance in Man database, the leading repository for human genetic disease data (also at Johns Hopkins) and, it is hoped, the mouse genome mapping database at the Jackson Laboratory in Florida, Lucier says.

Initially, copies will be held on mainframe computers at Johns Hopkins, and at a site in the United Kingdom - probably the Medical Research Council's Clinical Research Centre in North London. But there are plans to extend the service to the West German Cancer Centre in Heidelberg and later to Japan and Sweden, so that geneticists in those countries will not have to depend on sometimes unreliable international electronic communications to access the genome data. Peter Aldhous 